\title{
Correspondance
}

\section{Climate change and health}

Tn the Feb. 15 issue of $C M A \mathcal{A}$, the 1 lead editorial ${ }^{1}$ and a commentary by Sari Kovats and Andrew Haines ${ }^{2}$ refer to "global average surface air temperature" and "global average surface temperature" respectively. It appears that this is a key indicator upon which inferences about "global warming" are based. Yet I have not been able to find an adequate description of the method by which this measure is obtained. Even as a nonclimatologist, I recognize that temperature varies by location, altitude, season, hour of the day and numerous other factors. The concept of an "average global temperature" is therefore very difficult to grasp.

Are there internationally agreedupon sampling sites, sampling times and sampling procedures for such calculations? Have these been in place for decades and applied consistently to allow us to comment on global historical trends, let alone make projections for the future? Do we know the $95 \%$ confidence intervals around these average temperatures? Until I have more information about how this critical indicator is measured, I cannot evaluate the "evidence" for an impact on health.

\section{Kue Young}

Department of Public Health Sciences

University of Toronto

Toronto, Ont.

\section{References}

1. The Kyoto Protocol: In force? [editorial]. CMAf 2005;172(4):437.

2. Kovats RS, Haines A. Global climate change and health: recent findings and future steps [editorial]. CMAf 2005;172(4):501-2.

DOI:10.1503/cmaj.1050123

$\mathrm{S}$ ari Kovats and Andrew Haines, in their commentary on the interrelationship between global climate change and health, ${ }^{1}$ comment on the increase in deaths from extreme heat in Europe, particularly France, during summer 2003. It is important to note that some of these deaths were due to the elevated tropospheric ozone levels that accom- panied the high temperatures. ${ }^{2}$ In the Netherlands, about 400 deaths were attributed to ozone, ${ }^{3}$ and similar calculations have been done for France and Britain.

In 1990, I reviewed the implications of global warming at a parliamentary conference, ${ }^{4}$ noting that increased ozone levels would occur unless precursor emissions were reduced. Neither Canada nor the United States has succeeded in effecting major reductions in the emissions of oxides of nitrogen, and these are still substantial, as illustrated in a recent newsletter from the North American Commission for Environmental Cooperation. ${ }^{5}$ It has also recently been documented that tropospheric ozone levels are slowly rising over the North Atlantic. ${ }^{6}$

Fortunately, any steps taken to reduce carbon dioxide emissions will also reduce oxide of nitrogen emissions, with a consequent lowering of ozone levels. All physicians should agree with Kovats and Haines that it is urgent for Canada not only to implement the Kyoto Protocol but also to take an international leadership role in urging much greater reductions.

\section{David V. Bates}

Professor Emeritus of Medicine University of British Columbia Victoria, BC

\section{References}

1. Kovats RS, Haines A. Global climate change and health: recent findings and future steps [editorial]. CMA7 2005;172(4):501-2.

2. Schwartz J. How sensitive is the association between ozone and daily deaths to control for temperature? Am 7 Respir Crit Care Med 2005; 171:627-31.

3. Fischer PH, Brunekreef B, Lebret E. Air pollution related deaths during the 2003 heat wave in the Netherlands. Atmos Environ 2004;38:1083-5.

4. Bates DV. Health effects of global warming. In: Parliamentary Forum on Global Climate Change; 1990 Apr 23-24. Ottawa: House of Commons.

5. First look at air pollution from over 1,000 fossilfuel power plants in North America. Trio [serial online] Winter 2003-2004;(14). Available: www.cec .org/trio/stories/index.cfm?ed=14\&ID=159\&varlan =english (accessed 2005 Apr 27).

6. Lelieveld J, Van Aardenne J, Fischer H, DeReus M, Williams J, Winkler P. Increasing ozone over the Atlantic Ocean. Science 2004;304:1843-7.

DOI:10.1503/cmaj.1050057 s Sari Kovats and Andrew Haines 1 have pointed out in a recent commentary, ${ }^{1}$ our world is warming up. Climate models predict that this increase in mean annual temperature will continue for the rest of the 21st century. Whatever the reasons for the temperature increase, climate change may have a greater impact on ecological processes than previously realized. ${ }^{2}$

There is mounting evidence that global climate change has extended growing seasons, changed distribution patterns and altered the phenology of flowering, breeding and migration. For migratory birds, the timing of arrival on breeding territories and overwintering grounds is a key determinant of reproductive success, survivorship and fitness. ${ }^{3}$

The Arctic Climate Impact Assessment (ACIA) report - the most comprehensive assessment of regional climate change ever undertaken - was released in November 2004. ${ }^{4}$ The report documents that the Arctic has experienced dramatic warming over the past 50 years, with winter temperatures increasing by as much as $3-4^{\circ} \mathrm{C}$. Over the past 30 years, the Arctic has lost almost a million square kilometres of sea ice, an area larger than Norway, Sweden and Denmark combined. ${ }^{4}$

Indigenous peoples and livelihoods are already severely affected by rising temperatures and sea levels, as are human settlements and economic infrastructure by thawing permafrost. These serious impacts will not occur decades in the future - they are being felt now. And they are being felt not just in remote islands halfway around the world, but also in some of the world's richest countries. Glacier retreat in Nepal, Peru and Switzerland, anomalous heat waves in France, and increasing sealevel and salt-water encroachment in Kiribati, Bangladesh and the United States are just a few examples of impacts related to climate change.

For several decades now we have been acutely aware of the increasingly intensifying effect that environmental degradation has on human health. Health experts are becoming more and 
more concerned about the potential impact on public health. ${ }^{5}$ The medical community must become more aggressively involved in combating future global environmental problems.

\section{Ediriweera B.R. Desapriya}

Department of Pediatrics

Centre for Community Child Health

Research

Vancouver, BC

\section{References}

1. Kovats RS, Haines A. Global climate change and health: recent findings and future steps [editorial]. CMA7 2005;172(4):501-2.

2. Bernt-Erik S. Weather ruins winter vacations. Science 2000;288(5473):1975-6.

3. Cotton PA. Avian migration phenology and global climate change. Proc Natl Acad Sci U S A 2003;100(21):12219-22.

4. Arctic climate impact assessment overview report. Oslo (Norway): Arctic Monitoring and Assessment Programme; 2004. Available: http ://amap.no/workdocs/index.cfm?dirsub=\%2FACIA \%2Foverview (accessed $200520 \mathrm{Feb}$ ).

5. Alfven G, Arman T. [The greenhouse effect an issue for the medical profession.] Lakartidningen 2004;101(37):2834-5. Swedish.

DOI:10.1503/cmaj.1050104

\section{[One of the authors responds to Kue} Young:]

Olobal average surface temperature $\mathcal{T}$ is an established climatologic metric to describe global warming (or cooling). ${ }^{1,2}$ Further information is available in the assessment of Working Group I of the Intergovernmental Panel on Climate Change. ${ }^{3}$

\section{Sari Kovats}

Lecturer

Public and Environmental Health

Research Unit

London School of Hygiene and Tropical

Medicine

London, UK

References

1. Jones PD, New M, Parker DE, Martin S, Rigor IG. Surface air temperature and its changes over the past 150 years. Rev Geophys 1999;37:173-99.

2. Jones PD, Moberg A. Hemispheric and largescale surface air temperature variations: an extensive revision and an update to 2001. 7 Climate 2003;16:206-23.

3. Working Group 1. Climate change 2001: the scientific basis [online]. Intergovernmental Pane on Climate Change; 2001. Available: www.grida .no/climate/ipcc_tar/wg1/index.htm (accessed 2005 Jun 24).

DOI:10.1503/cmaj.1050136

\section{Choice of antihypertensives after acute ischemic stroke}

ndrea Semplicini and Lorenzo Calò address the thorny issue of managing hypertension in the setting of acute ischemic stroke. ${ }^{1}$ They emphasize the importance of selecting rapidly reversible agents "in case neurologic signs and symptoms worsen with the blood pressure reduction." They also mention the recommendations of both the American Stroke Association and the European Stroke Initiative in selecting an appropriate pharmacologic agent, either labetalol or sodium nitroprusside.

Labetalol given intravenously has an onset time of 5 minutes, a peak effect at 20-30 minutes and a duration of action of 3-6 hours. ${ }^{2}$ In contrast, sodium nitroprusside has an onset time of less than 1 minute, a peak effect at 1-2 minutes and a duration of effect of 2-5 minutes. ${ }^{2}$ Given these differences, is there really a role for labetalol (or any other agent, save intravenous nitroglycerin if acute myocardial ischemia is a concern) in a setting where the ability to rapidly titrate the drug to effect is of serious import?

\section{Seamus Donaghy}

West Lincoln Memorial Hospital

Grimsby, Ont.

\section{References}

1. Semplicini A, Calò L. Administering antihypertensive drugs after acute ischemic stroke: timing is everything. CMA7 2005;172(5):625-6.

2. Fisher NDL, Williams GH. Hypertensive vascular disease. In: Kasper DL, Fauci AS, Longo DL, Braunwald E, Hauser SL, Jameson JL, editors. Harrison's principles of internal medicine. 16th ed. New York: McGraw-Hill; 2005. Table 23010, p. 1478.

Competing interests: None declared.

DOI:10.1503/cmaj.1050113

\section{[The authors respond:]}

W e did not discuss the relative merits of labetalol and sodium nitroprusside in our article, ${ }^{1}$ and thank Seamus Donaghy for pointing out the differences in duration of action between these 2 drugs.
It is true that labetalol has a longer duration of action than nitroprusside, but for the treatment of patients with acute stroke, we rely more on the fact that the onset of therapeutic effect is similar (in the range of a few minutes). Therefore, it is safe to start with a small (20 mg) intravenous bolus of labetalol, check if the desired blood pressure is achieved within 20-30 minutes and, if not, administer another bolus. In this way, it is possible to achieve a gradual reduction in blood pressure, without the risk of a too-rapid rise in blood pressure when the drug effect decreases.

Other considerations limit the use of nitroprusside: it requires continuous blood pressure monitoring (because of its short duration of action), it has toxic effects, and it is not readily available in many institutions.

Andrea Semplicini

Lorenzo A. Calò

Department of Clinical and Experimental Medicine

University of Padua Medical School

Padua, Italy

\section{Reference}

1. Semplicini A, Calò L. Administering antihypertensive drugs after acute ischemic stroke: timing is everything. CMAJ 2005;172(5):625-6.

Competing interests: None declared.

DOI:10.1503/cmaj.1050117

\section{Rehabilitation and acute stroke care}

$\mathrm{Q}$ uality-of-care indicators provide an important framework for developing consistent high-quality care. The commentary by Patrice Lindsay and associates ${ }^{1}$ provides a framework for acute stroke care but fails to address the necessary link to rehabilitation services.

Although rehabilitation is acknowledged in the article's online appendix as an important component of stroke care, ${ }^{2}$ the lack of a specific indicator addressing this link during acute care diminishes the importance of timely assessment of rehabilitation needs. 